\title{
A CONSTRUCÃO DO LEITOR EM O BATALHÃO DAS LETRAS DE MARIO QUINTANA
}

Juliana Maffeis ${ }^{1}$

Resumo: O poeta Mario Quintana divide sua obra entre o público infantil, para quem destina $O$ batalhão das letras - obra analisada neste estudo - e o público adulto, para quem dirige a maior parte da literatura que produz. Poeta bastante preocupado com a sua criação, enxerga no leitor um crítico. Em $O$ batalhão das letras, Quintana faz uso de recursos como o humor, a ironia e a linguagem cotidiana para falar do mundo onde crianças e adultos habitam em harmonia. A obra $O$ batalhão das letras teve edições revisadas em 1985, 1987, 1995 e 1996 e a necessidade de modificá-la sempre que possível acompanha a obra do autor. Neste artigo, analisamos o destinatário da obra através da teoria proposta em "O ato da leitura", de Wolfgang Iser, com o objetivo de identificar como o leitor de Mario Quintana é, por ele, construído. Este exercício foi realizado a partir de uma ação leitora que permitiu a mobilização de oficinas criativas ministradas para crianças na Casa de Cultura Mario Quintana, em Porto Alegre, em que utilizamos os poemas contidos em $O$ batalhão das letras.

Palavras-chave: Formação do Leitor. Leitura. Educação. Estética da recepção. Poesia.

\section{Considerações iniciais}

Um ateliê colorido com janelas enormes. $O$ sol, que entra sem pedir licença, ilumina e aquece o ambiente. Em cima da mesa há livros, papéis, canetas coloridas e garrafinhas contendo um poema manuscrito dentro. Um grupo de crianças chega, entra, senta, observa tudo: a arquitetura da Casa de Cultura Mário Quintana enche os olhos dos grandes e dos pequenos. Antes de abrir o livro, a leitura já começou a ser realizada por cada detalhe observado, comentado, emocionado. Quando a turma, enfim, percebe que faremos uma atividade, iniciamos uma conversa que nos leva à leitura dos poemas. Dessa forma, estamos investigando a questão norteadora deste estudo: como Mario Quintana constrói o lugar do leitor na obra O batalhão das letras?

Para pensar nesse movimento, buscamos analisar o leitor por meio da Estética da recepção e da Teoria do efeito, do crítico literário alemão Wolfgang Iser. Justificamos o interesse em tentar solucionar tal questão através das

\footnotetext{
1 Mestranda em Letras, na área de Escrita Criativa (PUCRS), com especialização em Teoria e Prática na Formação do Leitor (UERGS) e graduação em Letras - Língua Portuguesa e Literaturas (PUCRS).

Revista de Letras JUÇARA, Caxias - Maranhão, v. 03, n. 01, p. 18 - 36, ago. 2019|18
} 
Oficinas de poesia, atividades lúdico-pedagógicas, ministradas na Casa de Cultura Mario Quintana, antigo hotel onde residiu o poeta, no centro histórico do município de Porto Alegre, localizado no Rio Grande do Sul, e que hoje funciona como centro cultural em sua homenagem. Nas oficinas, trabalhamos com diversos poemas de Mario Quintana com crianças de até 12 anos, mas podemos constatar que era na leitura de $O$ batalhão das letras que a atenção do grupo de crianças era, realmente, capturada.

Em função deste fato, inicia a curiosidade e a busca de respostas que justifiquem a reação diferenciada das crianças e decidimos centrar nosso olhar ao tratamento que o poeta dava ao seu leitor, especificadamente, nesta obra. Buscamos, então, teoricamente, a Estética da recepção e a Teoria do efeito para contribuir nesta análise que objetiva compreender o leitor construído por Mario Quintana. A partir da euforia das crianças que frequentavam as Oficinas de poesia quando em contato com os poemas de $O$ batalhão das letras, optamos por esta obra como objeto de estudo, principalmente para pensar nas questões que dizem respeito à relação com o público-leitor.

Com frases curtas, ênfase no som, aliterações e conteúdo questionador, estudos anteriores comprovam este esse cuidado de Mario Quintana com o escrito, em que chegou, até mesmo, a reescrever alguns de seus poemas a cada nova edição, na tentativa de envolver (ainda mais) o leitor da atualidade:

\author{
O G tem forma de assento \\ Para o prazer da leitura, \\ Um prazer que sempre dura \\ E não se esvai num momento... \\ (QUINTANA, 1998, p. 30) \\ O G é uma letra importante, \\ Como assim logo se vê: \\ Com um $\mathrm{G}$ se escreve GLOBO \\ E o GLOBO GIRA com G \\ (QUINTANA, 1998, p. 30)
}

Fátima Eponina Miranda de Lima, que, em 1998, escreveu sua dissertação de mestrado baseada nessa obra de Quintana, observa que o poeta, após produzir os poemas de $O$ batalhão das letras, negou a existência desse

Revista de Letras JUÇARA, Caxias - Maranhão, v. 03, n. 01, p. 18 - 36, ago. 2019| 19 
trabalho por pensar não ter conseguido realizar uma obra inovadora, haja vista ter se limitado a criar de uma forma lírica padrão, em quadras. Assim, tentando livrarse de rótulos, Quintana usa algumas estratégias para fazer com que seu texto seja atualizado pelo leitor, previstas pela Teoria da Estética da Recepção, como veremos.

\section{O lugar do leitor}

A teoria da Estética da recepção, elaborada em 1967 pelo grupo de Konstanz, na Alemanha, com Hans Robert Jauss e Wolfgang Iser à frente, fez uma interpretação sobre a permanência dos clássicos entre os leitores modernos e uma análise das alterações sofridas em sua leitura. $O$ estudo propõe uma reformulação da historiografia literária e da interpretação textual, procurando romper com o exclusivismo da teoria de produção e representação da estética tradicional, pois considera a literatura uma relação dinâmica entre autor, obra e leitor.

No artigo Recepção e leitura no horizonte da literatura, a autora Regina Zilberman (2008) apresenta a Estética da Recepção como uma corrente que, na Alemanha de 1960, substitui a Teoria do Texto pela Teoria do Leitor. O leitor, de acordo com as suas experiências, é capaz de atualizar a obra e a literatura, assim, torna-se um sistema composto pela produção, recepção e comunicação.

Wolfgang Iser, em $A$ literatura e o leitor, considera autor, texto e leitor elementos indissociáveis e afirma que dentro dessa relação ocorre a produção de algo que antes não existia. O novo produto construído não é determinado somente pela estrutura do texto, mas junto a um esquema de representação o qual o teórico chama de "jogo do texto". Tal conceito apresenta as operações ocorridas dentro do processo textual e não se envolve com possíveis significações fora do próprio texto, pois "os autores jogam com os leitores e o texto é o campo do jogo" (ISER, 1979, p. 107) e essa relação autor-texto-leitor gera um resultado final. 
De acordo com o autor, o texto é o resultado da intenção do autor e é composto por um mundo que necessita da identificação do leitor. Para que tal processo ocorra, o texto escrito incita o leitor a imaginar uma realidade para interpretá-la, visualizando formas possíveis do mundo real, muitas vezes, diferentes daquelas oferecidas pelo autor. Deste modo, o texto passa a sofrer modificações referenciais. Essa transgressão concede vida ao texto ficcional, indicando o mundo textual "não como uma realidade, mas como se fosse realidade" (ISER, 1979, p. 107).

Cada leitor apresenta uma interpretação acerca da representação sugerida pelo texto. Porém, o texto lido por diferentes leitores passa a prosperar a ideia do jogo, que multiplica as diferenças e soma resultados. Por admitir leitores com diferentes desempenhos no ato da recepção, Iser (1979) revela que não há vencedores no jogo, pois quem ganha é o próprio esquema tático, que se desenvolve ao libertar significados.

Segundo Iser (1979), o jogo do texto só poderia ser avaliado levando em consideração as suas possibilidades, por meio de estratégias empregadas no jogo ou pelos jogos realizados dentro do texto. A transformação, para Iser (1979, p. 115), chega ao estado de fruição através da participação imaginativa do leitor, pois a transformação é apenas um meio para o fim e não um fim em si mesmo.

O texto literário é o campo onde leitor e autor jogam. Iser (1979) divide este espaço em três níveis. São eles: o estrutural, o funcional e o interpretativo. $\mathrm{O}$ estrutural é o nível que compreende a estrutura do texto, que visa mapear o espaço da escritura; o funcional explica as metas interpretativas a partir das respostas para os motivos pelos quais jogamos e as razões pelas quais devemos jogar, pensando na real necessidade do jogo; e o interpretativo sugere 0 significado atribuído pelo leitor do texto.

Iser observa, ainda, que todo texto é emitido para que o leitor o atualize, cabendo somente a ele tal incumbência. São as diferenças de pensar, agir e sentir do leitor que atualizam o texto. Ainda que o autor estude seu destinatário ao máximo, este mesmo autor apenas poderá se empenhar em estimular um efeito 
preciso. O efeito estético passa a ser analisado na relação dialética entre texto, leitor e sua interação.

A concepção teórica elaborada por Iser (1996), a Teoria do Efeito, tem sua origem nos estudos de Roman Ingarden (1893-1970) e, como o próprio nome diz, analisa os efeitos da obra literária provocados no leitor, por meio da leitura. Iser (1996)

privilegia a experiência da leitura de textos literários como uma maneira de elevar a consciência ativamente, realçando o papel da mesma na investigação de significados. Tal teoria considera que para o leitor atualizar o texto, torna-se necessária desenvolver uma estratégia textual que the confira uma série de competências capazes de cooperar com o movimento interpretativo do texto.

Além disso, é comum acontecer de a competência do leitor não suprir as necessidades para a interpretação do texto (pelo fato de o leitor não ser aquele modelo idealizado pelo leitor) e, desta forma, o texto não atualizará todo seu conteúdo, mas, ainda assim, criará algo novo, que originará um resultado próprio. Assim, entendemos o texto como a significação do produto de efeitos experimentados.

Iser (1979) afirma que os atos de apreensão são orientados pelas estruturas do texto, mas não são controlados por elas, pois o texto contém elementos de indeterminação, que fornecem e fortalecem a comunicação com o leitor e, ainda, esclarece que seja qual for a forma do texto, ele não pode ser considerado um documento, pois sempre irá sugerir uma reformulação de uma realidade já considerada.

A Teoria do efeito baseia-se no texto e sua estrutura enquanto que a Estética da recepção fundamenta-se nos leitores e suas vivências. Na teoria do efeito pensa-se na qualidade de um texto literário, que está na capacidade de produzir algo que eles próprios não determinam e esta competência se afirma dentro do leitor. Na teoria da recepção busca-se o leitor ideal, que procura solucionar qualquer problema ficcional, mas ainda não se pode sugerir que este leitor decodifique o texto com a intenção de seu autor. 
Antoine Compagnon, crítico francês, analisa o destinatário de uma obra no capítulo "O leitor", da obra O demônio da teoria, de 2001. Neste capítulo, o autor traz fatos históricos que analisam a figura do leitor dentro da teoria literária. Compagnon afirma que o lugar do leitor, dentro das análises literárias, era limitado a descrever imposições textuais objetivas que regulam o desempenho do leitor concreto, desde que, evidentemente, ele se comporte de acordo com o que o texto espera dele. Assim, a leitura real passa a ser negligenciada em proveito de uma teoria. Na busca da definição de um leitor competente ou ideal, o leitor que pede o texto deve se curvar à expectativa do mesmo.

O leitor empírico, a má compreensão e as falhas na leitura perturbam todas as abordagens teóricas que circundam a figura do autor ou ao texto. Surge, então a tentação de ignorar o leitor e toma-se a iniciativa de formular uma teoria como uma disciplina da leitura ou uma leitura ideal, visando a remediar as falhas dos leitores empíricos. Para Compagnon, "a leitura tem a ver com a empatia, a projeção, a identificação. Ela maltrata obrigatoriamente o livro e se adapta às preocupações do leitor" (2001, p. 144) e o leitor aplica aquilo que lê à sua própria situação.

Nesse trabalho, Compagnon (2001) afirma que, para Proust, cada leitor é, quando lê, o próprio leitor de si mesmo. A obra do escritor somente é uma espécie de instrumento de ótica que ele oferece ao leitor a fim de permitir-Ihe discernir aquilo que sem o livro talvez não tivesse visto em si mesmo. Deste modo, pode-se afirmar que o leitor é livre e seu objetivo é menos compreender o livro do que compreender a si mesmo através do livro; aliás, ele não pode compreender o livro se não compreende a ele próprio graças a esse livro.

No ato da leitura, a expectativa está em função daquilo que já foi lido - não somente no texto que lemos, mas em outros textos outras leituras já realizadas. A leitura procede, pois, em duas direções: ao mesmo tempo para trás e para frente, usando suas referências advindas 
da vivência como leitor e seguindo adiante no preenchimento de um novo texto a ser interpretado. Segundo Compagnon (2001), o papel do leitor real é ao mesmo tempo ativo e passivo.

Para Iser (1979), a obra literária tem dois polos: o artístico e o estético. O artístico é o texto do autor e o estético é o preenchimento efetuado pelo leitor. $O$ leitor passa por diversos pontos de vistas oferecidos pelo texto e se relaciona com diferentes sentidos. Assim, ele põe a obra em movimento, e se põe também neste movimento. Para Compagnon (2001), o sentido é um efeito experimentado pelo leitor e não um objeto a ser definido. O objeto literário é autêntico e surge na interação do texto com o leitor, em constante movimento.

A leitura acontece na expectativa e na modificação desta expectativa, pelos encontros imprevistos ao longo do caminho que se parecem com uma viagem através do texto. Para descrever o leitor, Compagnon recorre à metáfora do viajante, de Iser, que segue:

\begin{abstract}
Para descrever o leitor, Iser recorre não à metáfora do caçador ou do detetive, mas à do viajante. A leitura, como expectativa e modificação de expectativa, pelos encontros imprevistos ao longo do caminho,parece-se com uma viagem através do texto. O leitor, diz Iser, tem um ponto de vista móvel, errante, sobre o texto. O texto nunca está todo, simultaneamente presente diante de nossa atenção: como um viajante num carro, o leitor, a cada instante, só percebe um de seus aspectos, mas relaciona tudo o que viu, graças à sua memória, e estabelece um esquema de coerência cuja natureza e confiabilidade dependem de seu grau de atenção. Mas nunca tem uma visão total do itinerário. (COMPAGNON, 2001, p.152)
\end{abstract}

Um texto, afirma Umberto Eco, crítico italiano, (2011, p. 42), por possuir muitos atos de interpretação, é emitido para alguém que o atualize. Por conseguinte, cabe ao autor empenhar-se em estimular um efeito preciso. Para Iser (1979), o texto literário oferece papéis aos seus leitores e esses papéis se definem como uma estrutura do texto e do ato de leitura. A estrutura representa apenas uma visão do autor e é compreendida junto da perspectiva do leitor, podendo essas perspectivas cruzarem-se no campo da interpretação ou não. 
Assim, o sentido do texto é atualizado com a ajuda da imaginação do leitor, que se encontra definitivamente no mundo do texto.

De maneira semelhante como Compagnon (2001) se apropria da metáfora de Iser, Umberto Eco (1994) apodera-se da ideia criada por Jorge Luis Borges no conto "O jardim de caminhos que se bifurcam", que faz de "bosque" uma metáfora para o texto. Umberto Eco afirma no livro Seis passeios pelos bosques da ficção que, "mesmo quando não existem num bosque trilhas bem definidas, todos [os leitores] podem traçar sua própria trilha, decidindo ir para a esquerda ou para a direita de determinada árvore e, a cada árvore que encontrar, optando por esta ou aquela direção" (1994, p.12).

$\mathrm{O}$ ato da leitura prevê o preenchimento do texto por parte leitor. Cada momento da leitura implica uma mudança de perspectiva e a comunicação se organiza na mudança de ponto de vista. Durante o ato da leitura, o leitor projeta suas expectativas acumuladas até que a leitura reaja a ele próprio, produzindo e experimentando um texto vivo.

De acordo com o teórico alemão, o leitor aparece como estrutura textual, dando origem ao leitor implícito, e como ato estruturado, surge a leitura real. A leitura se apresenta como uma resolução de enigmas e espera que o leitor use todas as informações contidas no texto até então. Esta é uma tarefa programada pelo texto, que pode oferecer alguns obstáculos ao leitor.

Iser (1979) também observa que a estrutura textual e 0 ato da leitura se relacionam como intenção e preenchimento. A concepção do leitor implícito não é a negação de um leitor real, mas o resultado da tensão que resulta do contato entre texto e leitor: aquilo que o texto diz junto daquilo que o leitor pensa que $o$ texto diz. Assim, o leitor jamais pode obter a certeza de sua visão como correta, precisando reunir os códigos que orientam esta informação que estão fragmentados no texto.

Umberto Eco (2011), em seu estudo sobre narratologia, Lector in fabula, afirma que um texto representa uma cadeia de artifícios de expressão que devem ser atualizados pelo destinatário (leitor). Um texto distingue-se de outros tipos de expressão por sua maior complexidade em função de ser entremeado de não- 
ditos. Para Eco (2011), o "não-dito" significa não manifestado em superfície, a nível de expressão: mas é justamente este não-dito que tem de ser atualizado junto ao texto, acima de qualquer outra mensagem e pressupõe movimentos cooperativos, conscientes e ativos da parte do leitor. Para o teórico, o texto necessita da ajuda de alguém para funcionar:

\begin{abstract}
O texto está entremeado de espaços em brancos, de interstícios a serem preenchidos, e quem o emitiu previa que esses espaços e interstícios seriam preenchidos e os deixou branco por duas razões. O texto é um mecanismo preguiçoso (ou econômico) que vive da valorização de sentido que o destinatário ali introduziu; e somente em casos de estremo formalismo, de extrema preocupação didática ou de repressividade o texto se complica com redundância e especificações ulteriores - até o limite em que se violam as regras normais de conversação. Em segundo lugar, porque, à medida que passa a função didática para a estética, o texto quer deixar ao leitor a iniciativa interpretativa, embora costume ser interpretado com uma margem suficiente de univocidade. Todo texto quer que alguém o ajude a funcionar. (ECO, 2011, p.57)
\end{abstract}

Como todo texto quer que alguém o ajude a funcionar e nem sempre a competência do destinatário é a mesma do emitente, Eco previu que o leitormodelo ocorre na expectativa de mover o texto de modo a construir um leitor com tal função, que funcionasse junto ao texto.

Para Iser (1979), o leitor atraído pelo texto é também "jogado" pelo texto, como uma peça indispensável ao jogo. $O$ jogo do texto se encena ao leitor, a quem é ofertado o papel que habilita a realização do cenário apresentado. $O$ jogo do texto não acontece como um espetáculo o qual o leitor observa na plateia, mas como um acontecimento que envolve o leitor no processo de encenação. A transformação, segundo Iser (1979), que ocorre dentro do jogo do texto, seja em termos de semântica, na obtenção de experiências ou por meio do prazer "representa uma tendência de acordo com a qual o jogo do texto pretende ser realizado" (1979, pg. 117).

Enfim, cabe a questionamento sobre o jogo: afinal, o que é o jogo e por que jogamos? Iser acredita que o jogo seja uma atividade que apresenta seu fim em si mesmo e explora os limites do possível em vista da possibilidade de um todo e, ainda, encena um meio de transpor fronteiras, encenando uma Revista de Letras JUÇARA, Caxias - Maranhão, v. 03, n. 01, p. 18 - 36, ago. 2019 | 26 
transformação, revelando como se faz uma encenação e até mesmo, conduzindo o leitor a um caminho de acesso outrora inacessível.

O leitor que encontra sua consciência no momento da leitura encontra meios para preencher os vazios da estrutura do texto. O texto literário tem abertura para múltiplos sentidos e a mudança destes próprios sentidos para o mesmo leitor, já que a obra possui camadas de significação que podem se revelar diferentes a cada nova leitura. Eco (2011), atenta para Barthes, quando este afirma que a obra de arte não convida somente a um ato de cognição, mas a uma participação afetiva, que põe em jogo a totalidade da pessoa.

\section{O lugar do leitor n'O batalhão das letras}

Mario Quintana escreve $O$ batalhão das letras na forma de quadrinhas, poemas de quatro versos, com exceção à letra W, que é uma septilha, poema de sete versos. O ritmo dos versos é redondilha maior, em que todos os poemas apresentam sete sílabas. Seguindo a classificação contida em Versos, sons e ritmos, de Norma Goldstein, há rimas pobres, com palavras rimadas na mesma categoria gramatical e rimas ricas, com palavras rimadas não pertencentes à mesma categoria gramatical. O conteúdo das quadrinhas é referente ao conhecimento popular e o poeta usa a imagem das letras na construção dos poemas prevendo a importância destas na vivência do seu leitor, uma criança em fase de alfabetização.

Ao longo da elaboração do texto, o poeta define quem é o seu leitor. Em Poesia Infantil, a autora Maria da Glória Bordini afirma que o texto literário possibilita à criança apreender os conteúdos de forma espontânea e lúdica. $\mathrm{O}$ leitor de $O$ batalhão das letras atualiza os sentidos dos textos, ricos em possibilidades de interpretação, por seu caráter estético aflorado. O leitor implícito, previsto no texto, objetiva construir um significado adequado a cada verso.

Com caráter pedagógico, a obra, que se dirige ao leitor em fase de alfabetização, também se estende a pais, professores e demais leitores da poesia 
infantil. Cada público ajuda a construir o texto de forma diferente e, assim, realiza diversos entendimentos sobre a obra. De acordo com a vivência de cada leitor, as indeterminações contidas no texto são preenchidas, ocupando os espaços vazios determinados pelo autor.

Cada letra, no poema, possui um tema. Podemos pensar que a própria letra é o tema do poema, porém, também se pode refletir sobre o papel da letra em iniciar uma conversa para envolver o leitor, como um pretexto para um diálogo. O tema, para Jauss, é a perspectiva com que o leitor se acha envolvido num determinado momento e o horizonte abarca os segmentos das perspectivas que fornecem os temas das fases anteriores da leitura, como as experiências do leitor que influenciarão o ato da leitura. Como se pode perceber na letra W, 0 poema conta a história de seu surgimento:

\author{
Era uma vez um M poeta \\ Que um dia, em busca de um rima, \\ Caiu de pernas pra cima \\ E virou um belo dábliu! \\ Coisa assim nunca se viu, \\ Mas é a história verdadeira \\ De como o dábliu surgiu... \\ (QUINTANA, 1995, p. 24)
}

Esta quadrinha sobre o "W" conta a "verdadeira história do seu surgimento" e, no ato da leitura, a criança (ou qualquer leitor predisposto) consegue imaginar e preencher o texto com significação própria e, assim, recriar o mundo por meio da imaginação. Basta que o leitor conheça a grafia da letra $M$ para adentrar na aventura proposta pelo poeta.

$\mathrm{O}$ ato da leitura implica que os leitores carreguem previamente alguns conceitos relacionados ao texto, pois esta bagagem ajudará no preenchimento das indeterminações surgidas com os vazios do texto. Por se tratar de um texto poético, $O$ batalhão das letras se abre para além dos significados de um texto pedagógico. O leitor implícito, uma suposta criança em fase de alfabetização, acompanha toda a obra a fim de atualizá-la com seus significados oriundos da vivência e da abertura para a ludicidade presente na obra. 
A criança pode não ostentar um repertório de leituras e experiências grandioso, em função do curto tempo de vida, porém, a sua imaginação faz com que a sua leitura contribua de maneira intensa para a significação do texto.

\author{
Com $\mathrm{C}$ se escreve CACHORRO \\ Confidente das CRIANÇAS \\ E que sabe seus amores, \\ Suas queixas e esperanças... \\ (QUINTANA, 1995, p. 5)
}

Ao conceber uma criança como seu leitor ideal, Quintana se preocupa com os efeitos possíveis de serem transmitidos no texto. Iser (1979) afirma a existência de um leitor implícito no texto que leva em conta a apreensão e o efeito da leitura e, para obter sucesso na comunicação é necessário que o texto de ficção selecione, do mundo real, um repertório de normas e convenções do ponto de vista histórico e estabeleça relações entre elas. Para apreender e selecionar as convenções, o poeta cria seu texto utilizando objetos, animais e situações que pertencem à realidade do leitor, e prevê as reações produzidas por representações, estruturando o mundo poético.

Para Bordini (1986), um bom poema, ou seja, um poema esteticamente eficaz, não deveria sofrer o processo de desgaste formal e temático, pois os padrões artísticos quando priorizados pela sociedade valem como experiência estética e ainda que estejam dentro de suas determinações podem atingir a qualquer idade. A autora concorda com a ideia de efeito e interação de Iser (1986), mostrando que a poesia infantil pode perdurar enquanto seus textos conseguem afetar leitores de diferentes idades e manter com eles algum tipo de intercâmbio significativo, no plano do prazer ou no da autoconsciência.

Bordini (1986) considera essencial o contato com a literatura para a formação da criança, pois ajuda no desenvolvimento da personalidade, no crescimento intelectual e afetivo, na compreensão do real e no exercício da consciência crítica. A autora também considera o potencial da poesia como "a coisa em si", encontrado apenas em construções poéticas apuradas, com valor 
alto estético e "não enquanto peça literária que atende os interesses ideológicos de pais e professores, editores, livreiros e críticos literários".

\author{
Com M se escreve MÃO \\ E agora vê que engraçado: \\ Na palma da tua mão \\ Tens um $M$ desenhado! \\ (QUINTANA, 1995, p. 15)
}

Em busca do $\mathrm{M}$ desenhado, crianças e adultos abrem a palma da mão após a leitura. Essa reação é um reflexo não somente de uma ordem contida no poema, mas da curiosidade da criança que busca compreender o mundo e, assim, se insere no texto.

Para Zilberman, a formação do leitor crítico se torna possível quando o livro oferece meios para que o indivíduo compreenda a si mesmo e a realidade que 0 cerca, proporcionando-lhe um embasamento mediante o qual se construa "uma concepção autônoma e crítica da vida" (ZILBERMAN, 2005, p. 29).

Mario Quintana seleciona seu público por meio do uso das letras do alfabeto português, descartando os não-falantes da língua e aproximando seus leitores a um resgate às parlendas e às cantigas populares. Este recurso facilita ao leitor a apreensão da obra, uma vez que o texto artístico constrói seu mundo por meio de objetos do mundo real e são ressignificados pelo autor e com a atualização do leitor, no ato da leitura.

Ao idealizar um texto poético e que sirva para alfabetizar, Quintana usa estratégias a fim de tornar seu texto compreensível para o leitor, possibilitando que ele o atualize. Porém, é preciso atentar para o desenvolvimento deste leitor que, por acontecer rapidamente, pode evidenciar a sua busca ou necessidade por novas interpretações ou leituras a todo o momento. Bordini (1986) apresenta uma questão importante sobre o desenvolvimento do leitor:

Na verdade, um bebê não pode "ler" Cecília Meireles. Uma criança de quatro anos não entende a graça de um poema-piada. Uma criança de oito anos não se interessa por poesia de denúncia social. Isso não quer dizer que aos quatro, oito ou doze anos, as crianças não apreciem poemas destinados às faixas anteriores. O problema todo está em desRevista de Letras JUÇARA, Caxias - Maranhão, v. 03, n. 01, p. 18 - 36, ago. 2019 | 30 
considerar o estatuto estruturalmente adaptativo do poema infantojuvenil, como se o jovem não estivesse em constante mudança das habilidades linguísticas e da bagagem experiencial que são o requisito básico para que compreenda e ame o poema em qualquer estágio de seu desenvolvimento. (BORDINI, 1986, p. 77)

Segundo o professor e crítico literário estadunidense, Harold Bloom (2001), a leitura "conduz à alteridade" e, assim, o leitor socializa suas experiências. $O$ ato de ler estimula o diálogo e revela uma função formadora e educativa. Dentro dos poemas de $O$ batalhão das letras, existe um diálogo entre 0 leitor e a voz poética e quando essa conversa ocorre é preciso que se estabeleça, segundo Bordini (1986), uma adaptação do discurso de autor adulto à faixa etária do leitor infantil a fim de neutralizar as diferenças sobre quem é o leitor do texto, evitando, assim, os artificialismos comumente originados na assimetria. No poema da letra I, percebemos o contato da voz-poética com o leitor:

O I é a letra do ÍNDIO

Que alguns chamam de ILETRADO...

Mas o índio é mais sabido

Que muito doutor formado!

(QUINTANA, 1995, p. 10)

Por se tratar de poesia, a obra se abre por meio das lacunas deixadas para o leitor questionar, ressignificar o mundo, ampliar seu horizonte de expectativas, elaborar sua capacidade crítica e se integrar ao processo de humanização, sem fronteiras uniformes dos escritos que tem como centro o adulto. E, ainda, no poema da letra I notamos que obra de cunho infantil comprova que a literatura não precisa ser manipuladora nem alienante, pois toda criança quer ser respeitada e poder ler livros, elaborados sem artificialismos, usando a fantasia para habitar no mundo.

Para habitar o mundo de Quintana, as crianças participantes da Oficina de Poesia eram capazes de preencher seus poemas com suas significações. Essas significações, durante 0 ato da leitura oral, as levaram a uma consideração pertinente ao seu universo de expectativa. Segundo Chartier (1998), a leitura é 
um todo que produz significado. Toda a representação ocorrida durante 0 ato da leitura deve ser levada em consideração. Não se deve pensar apenas efeitos que a leitura gera ou as interpretações a que se dispõe, mas em todas as descrições de posição de corpo, de duração temporal e de localização no momento em que se lê. Todos estes elementos são significativos e possuem a capacidade de causar reações intensas e sentimentos profundos durante o momento da leitura. A leitura vivenciada pelas crianças durante a Oficina de Poesia, constituiu um conjunto de ações, mentais e físicas, que permitiam uma experiência reflexiva sobre as situações, as personagens-letras e a subjetividade que se criam na alteridade e na interação.

\section{Considerações finais}

Considerado um dos grandes poetas do Brasil, Mario Quintana cria uma poesia que pensa o leitor. Assim, foi com o objetivo de revelar o lugar concedido à construção do leitor na obra de poesia infantil $O$ batalhão das letras, que se evidenciou a atualidade e a relevância da discussão aqui feita.

Ao investigar o lugar do leitor na poesia de Quintana, à luz dos pressupostos teóricos de Wolfgang Iser sobre 0 ato de leitura e, em especial, sobre o leitor construído no texto - os quais permitem entender a leitura como o ato de interpretação em que o leitor, uma construção textual, deve cooperar para a atualização dos sentidos do texto - foi possível constatar que o poeta traça o caminho de leitura na própria tessitura dos versos, produzindo uma poética de leitura que abre espaço para a formação do leitor.

Diante disso, retomamos a questão: qual é o lugar do leitor na poesia de Mario Quintana? Umberto Eco (1986, p. 285) afirma que a comunicação não veicula um só significado, porém, podemos cogitar a hipótese de que o lugar do leitor em Quintana é o lugar da criação: criar o poema é criar o sujeito e é também criar o leitor. 
$\mathrm{Na}$ perspectiva da teoria literária, a leitura esbarra nos limites da interpretação do leitor e, como solução, mesmo que as teorias recepcionais mantenham o foco no texto para tratar da leitura, podemos pensar que o leitor recria os poemas preenchendo as lacunas e vazios do texto literário. Ao utilizar a abordagem prevista pela Estética da Recepção, que considera a literatura uma relação dinâmica entre autor, obra e leitor e observa o leitor, de acordo com as suas experiências, foi possível verificar a atualização da obra pelo sistema composto pela produção, recepção e comunicação.

Levando em conta essa premissa, a parte final do trabalho destina-se a pensar acerca das peculiaridades da leitura dos poemas-quadrinhas analisadas dentro dos campos temáticos e expressivos que se fundem, já que o tema proposto (um alfabeto questionador) é o decurso da criação de significados que emergem a partir da interpretação das crianças.

O texto de Mario Quintana, após a criação, depende da identificação do leitor e passa a sofrer modificações que podem transgredir sua intenção. Porém, essa proximidade entre leitor-autor age como um facilitador na apreensão da obra, em que as crianças são capazes de assimilar seus poemas enquanto produto estético. A partir da sensibilização do leitor, o poeta chama seu leitor para ocupar os espaços de indefinição do texto que partem da interação: o gosto, a interpretação e a produção de novos significados que ocorrem no momento da leitura.

Para descrever um texto, J. L. Borges recorreu à metáfora do bosque, aludindo a inexistência de trilhas com segmentos bem definidos capazes de traçar uma leitura única, de interpretação correta ou direcionamento padrão. Para descrever o leitor, Iser lança mão da metáfora do viajante, referindo à leitura como uma viagem através do texto, cujo leitor possui um ponto de vista móvel e errante por não conseguir enxergar o texto num todo, como um viajante que observa o percurso pela janela de um trem também não é capaz de capturar a paisagem com totalidade. Arriscamos, então, pensar em uma metáfora para vislumbrar o lugar do leitor com a imagem de uma poltrona reservada. 
O leitor de O batalhão das letras é atraído pelo texto é também "jogado" pelo texto, como sugere uma das "regras" do Jogo do texto, de Iser. Cabendo às crianças leitoras uma atividade que explora os limites do possível em vista da possibilidade de transpor fronteiras e encenar uma transformação, os leitores acabam por revelar um caminho de acesso outrora inacessível.

Para Zilberman (2005, p. 29), a formação do leitor crítico somente se torna possível quando o livro oferece meios para que o indivíduo compreenda a si mesmo e a realidade que o cerca, a fim de proporcionar um embasamento capaz de construir "uma concepção autônoma e crítica da vida". As crianças que encontraram sua consciência no momento da leitura durante as Oficinas de Poesia encontraram também meios para preencher os vazios da estrutura do texto e puderam sentir a abertura da poesia para a multiplicidade de sentidos para afirmar que a obra de arte convida a ocupação da poltrona já reservada pelo autor, mas que necessita uma participação afetiva e efetiva para completar esta interação.

Este estudo contribui para o entendimento das razões da identificação das crianças com os textos de $O$ batalhão das letras, sendo possível - agora refletir sobre a importância do conhecimento da teoria da recepção para trabalhar com formação de leitores e mediação de leitura ao fazer uso pertinente dos recursos utilizados pelo autor e pelo texto, lugar onde o leitor pode se encontrar dentro da perspectiva de criação de sentido.

A poesia, gênero textual abordado, promove a imaginação daqueles que nela se submergem para dentro de si mesmos, suscitado novas experiências de autoconhecimento. Colaborar com esse processo pode levar o leitor a abandonar uma relação mecanicista com as obras e com o mundo, e elevá-los a uma posição de afastamento do real imediato proporcionado pelo cotidiano. $\mathrm{O}$ formador de leitor deve oportunizar tal mergulho ao conduzi-lo à abertura do caminho para uma interpretação crítica e a criação de uma existência lúdica.

Ciente das indagações lançadas nos espaços vazios do texto, o formador de leitor motiva as crianças-leitoras a uma incessante procura a respostas, delegando-Ihes a atribuição à qual o próprio Quintana muito já havia se 
debruçado. Em $O$ batalhão das letras, Quintana, reserva poltronas para seu público leitor: crianças em fase de alfabetização que estejam dispostas a encontrar as respostas de suas questões dentro de si mesmas com a liberdade que se realiza este exercício dentro de um texto poético.

As Oficinas de poesia realizadas contaram com poltronas reservadas, literal e figuradamente, onde as crianças acomodavam-se junto a um objetivo que ultrapassava a leitura de Quintana, mas convidados à leitura de si mesmas. Com poemas bastante trabalhados para sensibilizar 0 universo infantil, compreendemos - após este estudo - a preferência das crianças pela leitura dos poemas contidos em $O$ batalhão das letras, por se tratarem de textos que referenciam diretamente $\mathrm{o}$ mundo em que as crianças habitam, percebem, entendem e criam a sua existência no mundo.

\title{
READER'S CONSTRUCTION IN O BATALHÃO DAS LETRAS OF MARIO QUINTANA
}

\begin{abstract}
The poet Mario Quintana divides his work between the children's audience, for whom he intended $O$ batalhão das letras - work analyzed in this study - and the adult audience, for whom he directs most of the literature he produces. Poet quite concerned about his creation, sees in the reader a critic. In $O$ batalhão das letras, Quintana makes use of resources such as humor, irony and everyday language to speak of the world where children and adults live in harmony. The work O batalhão das letras had revised editions in 1985, 1987, 1995 and 1996 and the need to modify it whenever possible accompanies the author's work. In this article, we analyze the recipient of the work through the theory proposed in $O$ ato da leitura, by Wolfgang Iser, in order to identify how the reader of Mario Quintana is, by him, built. This exercise was carried out through a reading action that allowed the mobilization of creative workshops given to children at the Casa de Cultura Mario Quintana, in Porto Alegre, where we used the poems contained in $O$ batalhão das letras.
\end{abstract}

Keywords: Reader Formation. Reading. Education. Reception aesthetics. Poetry.

\section{Referências}

BLOOM, Harold. O'Shea. Como e por que ler. Rio de Janeiro: Objetiva, 2001.

BORDINI, Maria da Glória. Poesia Infantil. São Paulo: Ática, 1986.

CHARTIER, Roger (org.). Práticas de Leitura. São Paulo: Estação Liberdade, 1998.

COMPAGNON, Antoine. O demônio da teoria. Belo Horizonte: UFMG, 2003. 
COSTA, Luis Costa (org.). A literatura e o leitor. Textos de estética da recepção. São Paulo: Paz e terra, 1979.

ECO, Umberto. Lector in fabula. São Paulo: Perspectiva, 1986. . Obra Aberta. São Paulo: Perspectiva, 1991. 1994. Seis passeios pelos bosques da ficção. São Paulo: Companhia das Letras,

GOLDSTEIN, Norma. Versos, sons, ritmos. São Paulo: Ática, 1995.

LIMA, Fátima Eponina Miranda. O batalhão das letras: a história de um livro a caminho de seu leitor. Dissertação de mestrado. Porto Alegre: PUCRS, 1998.

ISER, Wolfgang. O ato da leitura. São Paulo: 34, 1996.

O jogo do texto. In: COSTA, Luis Costa (org.). A literatura e o leitor. Textos de estética da recepção. São Paulo: Paz e terra, 1979

QUINTANA, Mario. O batalhão das letras. 2 ed. Porto Alegre: Globo, 1995.

ZILBERMAN, Regina. Estética da recepção e história da literatura. São Paulo: Ática, 1989.

. Recepção e leitura no horizonte da literatura. 2005. Disponível em: http://www.scielo.br/scielo.php?pid=S1517106X2008000100006\&script=sci_arttext Acesso em 15 jan. 2015

Data da Submissão: 22/01/2019

Data da Aprovação: 18/07/2019 